\title{
Design and Analysis of an Improved Wave Glider Recovery System
}

\author{
J. Rice, L. A. Gish, J. Barney, Z. Gawboy, B. Mays, L. Moore, A. Nickell \\ Department of Naval Architecture and Ocean Engineering \\ United States Naval Academy \\ Annapolis, Maryland, USA \\ jrice@usna.edu,gish@usna.edu
}

\begin{abstract}
The Sensor Hosting Autonomous and Remote Craft (SHARC) Wave Glider system is an autonomous surface vehicle widely used for long-duration at-sea data collection and acoustic monitoring. The system is manufactured by Liquid Robotics Inc. (LRI) and consists of two components (1) a surface float housing sensors, batteries, solar panels, and communication systems, and (2) a submerged propulsor (glider) containing six hinged hydrofoils. A third component, a submerged body housing additional sensors, may be towed behind the propulsor. While system launch is relatively straight forward, recovery of the system is challenging and incurs high risk. Challenges include (1) the Wave Glider system contains multiple components, (2) forward motion of the system cannot easily be arrested, and (3) the ship conducting recovery operations often has a high freeboard. Need for an improved recovery system is desired, particularly for the United States Naval Oceanographic Office (NAVOCEANO), as current recovery methods require personnel in small boats or swimmers in the water to control the vehicle and attach lifting lines. These procedures are hazardous to both personnel and equipment and are limited to low sea states. This project, conducted by a team of five undergraduate students and two advisers, designed and evaluated multiple alternatives as viable recovery solutions. Based on design and operational requirements, the final proposed solution is two-part. The first is a remotely actuated inflatable lift bag attached to the stern of the submerged propulsor that will halt forward movement when inflated; and the second is a vertical cable loop mounted on the surface float to facilitate lifting of the float, propulsor and towed payloads. The proposed solution was demonstrated to be feasible and met all design requirements, with an emphasis on simplicity.
\end{abstract}

Keywords-wave gliders; autonomous vehicles; recovery methods

\section{INTRODUCTION}

The Sensor Hosting Autonomous and Remote Craft (SHARC) Wave Glider is an autonomous surface vehicle used for long-duration at-sea data collection and acoustic monitoring. The system is manufactured by Liquid Robotics Inc. (LRI), consists of a platform float, submerged propulsor (glider), optional towed payload, and is widely used across a myriad of industries, including defense, maritime domain awareness, environmental assessment and oil and gas [1].

There are currently two variants of the SHARC Wave Glider, the SV2 and SV3. While the SV3 is larger, and can carry heavier payloads [2], both variants are unique in that they harvest all energy from renewable sources - energy for propulsion is harvested from the ocean waves, and energy for onboard sensors is harvested from the sun [3]. Once deployed, the system can sustain on these energy sources for deployments up to one year [1]. During deployments, the SHARC Wave Glider communicates to a ground control station via secure iridium satellite links, receives updates and GPS way-points and continues on mission until it is time for shipboard recovery.

Launch and deployment of the SHARC Wave Glider is relatively straight forward. Recovery of the platform float, propulsor, and towed payloads, however, is challenging, particularly for vessels with high freeboard, such as the T-AGS 60 class oceanographic vessel, used by the United States Naval Oceanographic Office (NAVOCEANO). Current recovery procedures involve swimmers in the water and small boats in high sea states, and as such incur high risk. Limited commercial off-the-shelf solutions are available [4], but none currently meet all operational requirements.

The following proposed two-part solution is designed, analyzed, prototyped and laboratory tested by a team of five undergraduates and two advisers based on the SV2 Wave Glider variant and specific operational design criteria.

\section{WAVE GLIDER SPECIFICATIONS AND MECHANICS}

\section{A. Overview}

A necessary precursor to designing a SHARC Wave Glider recovery system is thorough understanding of the Wave Glider mechanics. LRI currently has two variants of the SHARC Wave Glider system, the SV2 and SV3, with the former slowly being phased out. While the SV3 is a more advanced and capable system, both variants consist of similar main parts that are connected by a flexible tether as shown in Fig. 1 [5].

The first main part of the system is a surface float that rides on the water's surface [5]. The surface float for both variants houses solar panels, command and control electronics, lifting rings, and various payload bays to store data collection and monitoring equipment [5].

Connected by a flexible and strong umbilical, the second part sits approximately four to six meters below the water's surface [5]. The second part is a submerged propulsor (glider) that contains six hinged hydrofoils. These hydrofoils move freely within the water column and provide forward (horizontal) thrust based on vertical motion of the system [5]. There is a small rudder on the rear of the propulsor that controls direction of the 


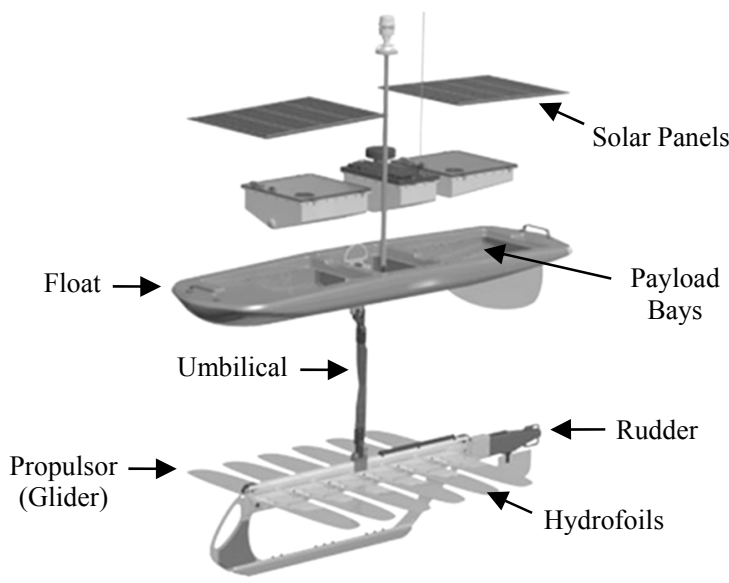

Fig. 1: Main components of the SHARC SV2 Wave Glider variant [5].

glider. The rudder is connected to the command and control box in the float via electric connections in the umbilical [5]. The rudder on the SV3 variant can also provide forward thrust when needed (high sea states).

Total dry weight and dimensions of both the SV2 and SV3 variants are provided in Table I [5].

TABLE I. SHARC Wave Glider Specifications

\begin{tabular}{|l|c|c|}
\hline & \multicolumn{2}{|c|}{ SHARC Wave Glider Variant } \\
\hline \multicolumn{1}{|c|}{ Specification } & $\boldsymbol{S} \boldsymbol{V} \mathbf{2}$ & $\boldsymbol{S} \boldsymbol{V}$ \\
\hline \multirow{2}{*}{ Float Dimensions } & $2.08 \mathrm{~m} \times 0.61 \mathrm{~m} \times$ & $3.05 \mathrm{~m} \times 0.81 \mathrm{~m} \times$ \\
& $0.25 \mathrm{~m}$ & $0.23 \mathrm{~m}$ \\
\hline \multirow{2}{*}{ Sub (glider) Dimensions } & $1.91 \mathrm{~m} \times 1.17 \mathrm{~m} \mathrm{x}$ & $2.13 \mathrm{~m} \times 1.42 \mathrm{~m} \mathrm{x}$ \\
& $0.43 \mathrm{~m}$ & $0.21 \mathrm{~m}$ \\
\hline Tether length & $5.79 \mathrm{~m}$ & $4.27 \mathrm{~m}$ \\
\hline Dry Weight & $90 \mathrm{~kg}$ & $150 \mathrm{~kg}$ \\
\hline Water Speed & $0.5 \mathrm{~m} / \mathrm{s}$ & $0.9 \mathrm{~m} / \mathrm{s}$ \\
\hline Max Payload Weight & $18.14 \mathrm{~kg}$ & $45.36 \mathrm{~kg}$ \\
\hline
\end{tabular}

\section{B. SHARC Wave Glider Mechanics}

For both variants, the SHARC Wave Glider's forward thrust operates on the free energy at the ocean's surface, available in the form of orbital motion. Wave action moves the surface float up and down, and this motion is transmitted to the submerged propulsor via a load-bearing umbilical [5]. As the propulsor moves up and down, horizontal lift is generated on the hydrofoils, causing forward motion [5].

Average speed of the SHARC Wave Glider variants are provided in Table I.

\section{Current Recovery Procedures and Challenges}

Current U.S. Navy recovery methods consist of deploying personnel in small boats to retrieve the wave glider vehicle, connect lifting lines, and then conduct multiple lifts to bring the float and propulsor onboard the recovery vessel or swimmers to attach lifting lines. These approaches present a safety risk to the recovering vessel, as well as the crew.

\section{DESIGN CRITERIA AND CONSIDERATIONS}

Based on pre-established operational needs, specific design requirements for this recovery system include the following:
1. Reliability: The system must be designed for reliability (capable of surviving $>12$ month deployments in various ocean environments without malfunction or degradation of SHARC performance).

2. Usability: The system can be operated using no more than three average strength crew members. Average crew member is assumed to be able to lift 75 pounds.

3. Simplicity: No excessive moving parts or electronics.

4. Configurability: Works with both SV2 and SV3 wave glider variants.

5. Recovery in Sea State 3 (threshold) or 4 (objective).

6. Compatible with existing host platform equipment (cranes, hoists, support systems, etc.).

7. No swimmer or small boat required.

\section{Design Alternatives}

Design alternatives were treated and analyzed as two separate parts: (1) a solution to stop forward motion of the Wave Glider via an operator-initiated action and (2) a solution to physically capture the Wave Glider components via hoisting them back to the ship's deck.

\section{A. Stopping forward motion}

As long as wave action on the surface persists, the glider will continue to thrust forward, making recovery of the system a challenge and high risk, even in low sea states. The first part of the recovery system design, therefore, focuses on how to stop forward motion. Forward motion can be stopped in two ways, (1) disrupting the flow of water over the propulsor fins by lifting the fins into a vertical position, or (2) increasing drag on the propulsor to counter forward thrust.

Two slowing devices are considered to address this problem, a lift bag and a drogue chute. The lift bag is a commercially available bag that inflates by a carbon dioxide or compressed air canister. When actuated the inflated bag lifts the entire propulsor system vertically through the water column to the water's surface. The drogue chute is also commercially available. It deploys similar to a parachute from either the float or propulsor body and provides drag to counteract forward thrust.

Both slowing alternatives require operator-initiated remote actuation.

\section{B. Physically capturing components}

Once stopped, all components of the Wave Glider system must be recovered from the water to the deck of the recovery vessel. To minimize risk to personnel, this phase must be completed without use of a small boat or divers in the water.

Design alternatives assume that the recovery vessel is able to maneuver alongside the glider's components once they are rendered stationary and that the only movements of the glider are from either the float and/or the propulsor bobbing on the surface. The design alternatives also assume that the recovery vessel has an onboard crane capable of hoisting all components of the system from the water to the vessel's deck. 
Three recovery solutions are considered: a deployable ring, a catamaran, and a large snare attached to the float. The deployable ring design is composed of a large, positively buoyant ring that attaches to the D-ring on the float. The ring is designed to be large and positively buoyant and thus, provide a large catch area for the ship's crane to attach. The catamaran design, or split hull surface recovery design, is based on the principles of multi-hull watercraft. It consists of two parallel hulls of equal size that are deployed from the recovery vessel's crane. Once in water, the parallel hulls provide a docking bay for the float and once the float is secured, the parallel hulls can then be recovered. The simplest of all three recovery solutions is the snare. The snare is a large vertical ring attached to the topside of the float and simply provides a large catch area for the recovery vessel's crane.

Regardless of alternative, once the propulsor is retrieved, current recovery methods using the LRI recovery tool are then used to recovery both the propulsor (which is now on the water's surface) and any towed payloads.

A decision matrix approach, utilizing weighting factors based on customer inputs, was used to select the best alternative for each part of the design solution.

\section{RECOMMENDED RECOVERY SYSTEM}

\section{A. Recommended Design}

Based on design criteria, the recommended design for part one of the recovery system is the inflatable lift bag attached to the stern of the submerged propulsor. In this design (Fig. 2), the lift bag, compressed air source, and actuation valve are all located in compact cylindrical housings mounted to the propulsor, so as not to interfere with other parts like the hydrofoils or rudder. The system is activated by an electric linear actuator, triggered by a remote radio signal from an operator on the recovery vessel. The linear actuator opens a valve to port the compressed air to the lift bag, rapidly inflating it. The buoyancy from the lift bag brings the propulsor to the surface, thus decoupling the surface float and propulsor and stopping forward motion.

Properly sizing the lift bag and canister to ensure adequate lift without degradation to SHARC operations due to increased drag is a critical part of lift bag and canister design. Initial minimal lift bag requirements is determined using Eq. (1), where

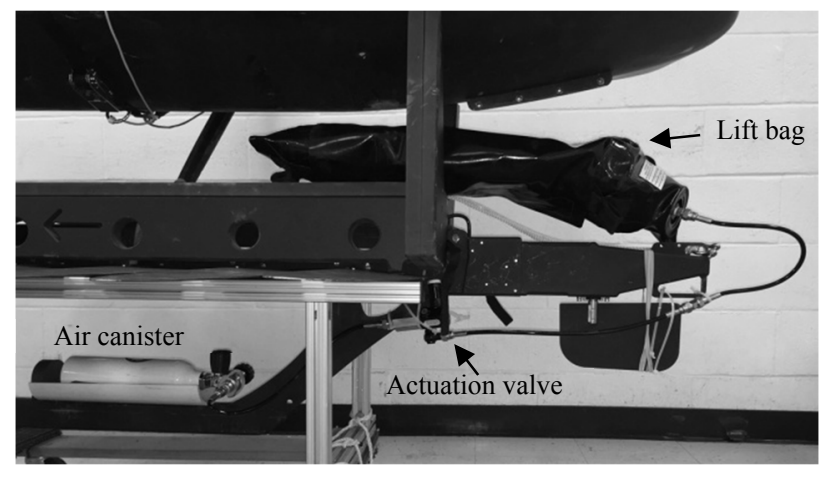

Fig. 2: Position of lift bag and air canister on propulsor.
$F_{B}$ is the weight of the propulsor in water and $V_{\text {sub }}$ is the submerged volume of the inflated lift bag.

$$
\mathrm{F}_{B}=\rho g \mathrm{~V}_{s u b}
$$

Required submerged inflated volume of the lift bag is calculated at 0.0664 cubic meters.

Prior to inflation, the lift bag is rolled to fit in cylindrical housing that is mounted to the propulsor. When rolled, the lift bag's cross section is reduced to one-tenth of its inflated cylindrical size. Commercial lift bags of the same volume vary in cross-sectional diameter and length. Because the size of the required housing, which is dependent on the cross-sectional dimensions of the rolled bag, impacts the amount of increased drag on the SHARC, consideration is taken to ensure ideal dimensions of the lift bag. Three lift bags of dimensions shown in Table II are used in laboratory testing.

TABLE II. Lift bag dimensions

\begin{tabular}{|c|c|c|}
\hline Bag Length (m) & $\begin{array}{c}\text { Inflated cross-sectional } \\
\text { diameter }(\mathbf{m})\end{array}$ & $\mathbf{1 / 1 0}$ diameter $(\mathbf{m})$ \\
\hline $0.406 \mathrm{~m}$ & $0.456 \mathrm{~m}$ & $0.046 \mathrm{~m}$ \\
\hline $0.508 \mathrm{~m}$ & $0.408 \mathrm{~m}$ & $0.041 \mathrm{~m}$ \\
\hline $0.610 \mathrm{~m}$ & $0.372 \mathrm{~m}$ & $0.037 \mathrm{~m}$ \\
\hline
\end{tabular}

The ideal gas law is then used to determine the minimal required air cylinder volume to inflate the lift bag at a depth of 7.6 meters and a canister pressure of $2 \times 10^{7}$ newton per square meter. The required calculated volume at operational depth, accounting for air volume in the lift bag, air cylinder, and connecting air hose, is 0.00058 cubic meters.

Although not shown in Fig. 2, the housing unit is a cylindrical unit with a hemi-spherical nose cone and is used to protect the lift bag from sea-fouling. The housing unit is attached to the rear top-side of the propulsor. The spine of the unit is connected to hinges that run the entire unit's length. Opposite the spine is the opening, which is held together by strapping. Once the lift bag starts to inflate, the bag provides enough outward force to open the unit and continue upward towards the surface.

Recommended design for part two of the recovery system based primarily on the design criteria of simplicity is the vertical cable loop, or SHARC snare, mounted to the centroid of the surface float's D-ring to provide a large capture area for a crane or hoist (Fig. 3). The SHARC snare sits atop of the surface float and is designed to act as a lifting arm. The proposed design has three main parts including, air springs, framed arms, and an arc cable. The air springs connect the float to the lifting arm. They are designed at 0.15 meters in height and are used to reduce surge, sway and heave forces from the crane as the float is being lifted. The framed arms are rectangular in shape with a height of 0.76 meters and are composed of hollow aluminum with an aluminum gusset in the top corners for added strength. The arc cable is a high-strength braided cable that arcs atop the aluminum frame. The highest point of the cable arc is 0.91 meters for a total of 1.82 meters from the bottom of the air 


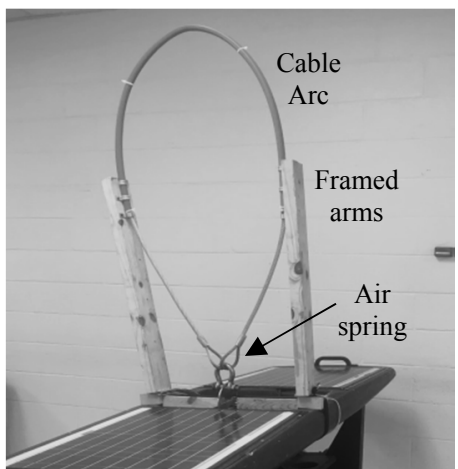

Fig. 3: SHARC snare mounted to surface float.

springs to the top of the arc. The design does not interfere with top-side antennas.

Once the SHARC is stopped, the recovery vessel maneuvers alongside and captures the surface float without need for a small boat or swimmer. The three components (surface float, propulsor, and towed payload (if used)) are then hoisted to the vessel deck individually in order as listed.

\section{B. Laboratory Testing of Lift Bag and Snare Hoist}

Prototypes of the systems described above were built on an SV2 Wave Glider. Static and dynamic lift tests, as well as snare lift tests, were then performed.

Tests were conducted in the United States Naval Academy's 116 meter length tow tank. Before testing the Wave Glider's umbilical was shortened to three meters to ensure safe clearance between the tank bottom and propulsor. The tested SV2 model did not have guidance capabilities and therefore, two lines were also attached to the float to use in case the Wave Glider veered toward tank walls. Waves with a period of 2.5 seconds and height of 0.15 meters were used to induce forward motion of the Glider.

Testing for both the lift bag and snare were successful; the propulsor quickly rose (average time from actuation of the air valve to when the propulsor was on the water's surface was approximately six seconds) and forward motion immediately stopped even though wave action continued (Fig. 4). The SHARC snare enabled easy capture and removal of the system with an overhead crane hook. The SHARC components remained in a stable, horizontal position while being lifted.

\section{Impacts on Wave Glider Operations}

Numerical flow simulations using SOLIDWORKS Flow Simulation were conducted to analyze increased drag on the system caused by mounting of the lift bag housing on the propulsor. Flow simulations were conducted at 1.0 meters per second, which is slightly faster than the maximum speed of both the SV2 and SV3 variants.

From flow simulation, the coefficient of drag, $\mathrm{C}_{\mathrm{D}}$, was calculated using the drag force equation (Eq. (2)), where $\mathrm{F}_{\mathrm{D}}$ is the force of drag, $\rho$ is the density of water (fresh water was used for numerical simulations), $A$ is the projected frontal area of the propulsor, and $v$ is the velocity.

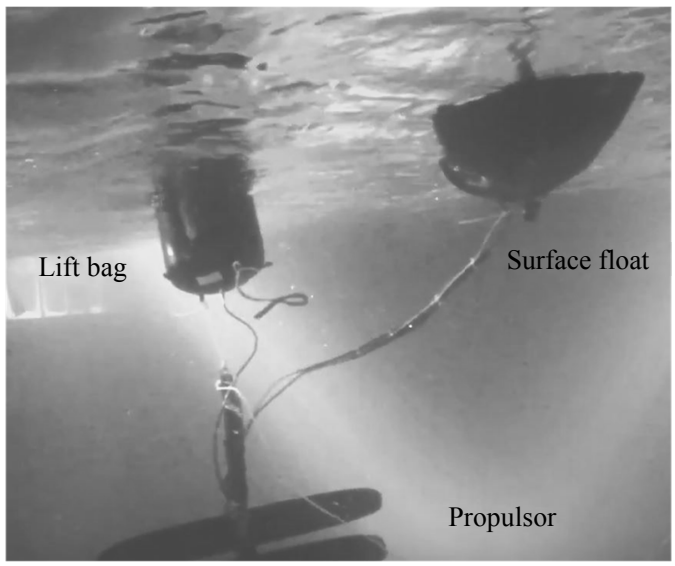

Fig. 4: Proof-of-concept test of propulsor lift bag in 116 meter tow tank.

$$
\mathrm{F}_{D}=\frac{1}{2} \rho A \mathrm{C}_{D} v^{2}
$$

Velocity of the SV2 with the mounted recovery device $\left(v_{\text {new }}\right)$ was then calculated using Eq. (3).

$$
\mathrm{v}_{\text {new }}=\sqrt{\frac{C_{\text {Dnew }}}{\mathrm{C}_{\text {Do }}}}
$$

Velocity profile results (Table III) indicate that a negligible $(\sim 5 \%)$ reduction in speed is caused by the increased drag (Fig. 5 and Fig. 6).

TABLE III. Flow Simulation Results

\begin{tabular}{|c|c|c|}
\hline & $\begin{array}{c}\text { Coefficient of Drag, } \\
\mathbf{C}_{\mathbf{D}}\end{array}$ & Reduction in Speed \\
\hline Propulsor (Fig. 5) & 0.427 & $5.5 \%$ \\
\hline $\begin{array}{c}\text { Propulsor with lift } \\
\text { bag (Fig. 6) }\end{array}$ & 0.478 & \\
\hline
\end{tabular}

\section{CONCLUSION}

LRI's SHARC Wave Glider is widely used by several organizations and industries, including the U.S. Navy. While the Wave Glider enables long-duration ocean data collection and

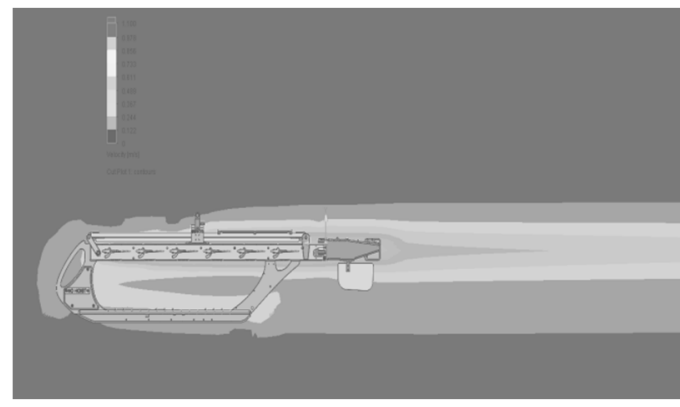

Fig. 5: SOLIDWORKS numerical simulation of drag on SV2 variant without recovery device. 


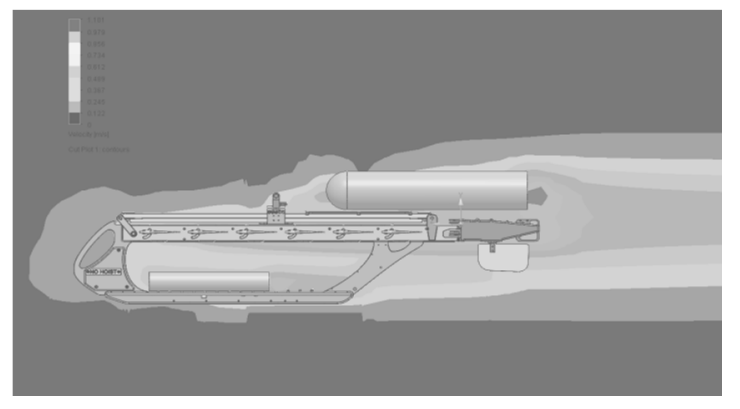

Fig. 6: Fig. 5: SOLIDWORKS numerical simulation of drag on SV2 variant with recovery device mounted to propulsor.

acoustic monitoring, recovery of the system incurs challenges and high risk. Based on specific design criteria, a team from the U.S. Naval Academy designed and evaluated multiple alternatives as viable recovery options, ultimately proposing a design solution. The proposed solution is two-part with a remotely actuated inflatable lift bag attached to the stern of the submerged propulsor that will halt forward movement when inflated; and a vertical cable loop mounted on the surface float to facilitate lifting of the float, propulsor and towed payloads. The proposed solution was demonstrated to be feasible and met all design requirements.

Future work includes finalization of the component design for the SV3 wave glider variant, and field testing of the recovery system in various sea states.

\section{REFERENCES}

[1] Liquid Robotics Inc. (n.d.). Liquid Robotics - Instrument the Ocean [Online]. Available: http://www.liquid-robotics.com.

[2] B. Coxsworth (2013, April 8). Liquid Robotics announces next generation of Wave Glider sea-going robot [Online]. Available: http://www.gizmag.com/liquid-robotics-wave-glider-sv3-aquatic/26977/.

[3] Autonomous Undersea Vehicle Applications Center. (n.d.) AUV System Spec Sheet - SHARC Wave Glider configuration [Online]. Available: www.auvac.org/configurations/view/247.

[4] UVS Pty Ltd. (2015). WG01 Wave Glider Recovery Device [Online]. Available: www.uvs.com.au.

[5] Model 08 Wave Glider User Manual, Version 2.41, Liquid Robotics Inc., Sunnyvale, CA, LRI Part Number-030-00025-02, 2010. 